\section{A CUT ABOVE OTHER FILE SYSTEMS}

DENTSPLY will be giving delegates at BDTA Dental Showcase 2013 the chance to discover the benefits of introducing ProTaper Next to their surgery. This new file system features a variety of new and innovative features which make ProTaper Next a cut above the rest.

The unique swaggering motion of ProTaper Next allows for an improved removal of debris, optimised canal tracking and reduced binding. This is all down to the file's off-centred rectangular cross section, which means that the file only ever connects with the canal in two places resulting in a greater space and a perfect tapered shape even in complex canals.

Visitors to the DENTSPLY stand at the show will be able to witness the simplicity and versatility of this system, which requires only one torque setting, one speed setting and two files in most cases.

To experience ProTaper Next for yourself visit DENTSPLY on stand G07 at this year's BDTA Dental Showcase.

www.dentsply.co.uk

\section{THE WHOLE RANGE AT AMAZING PRICES}

At Showcase WetH are launching a number of new products, developed as a result of working with customers to meet the needs of dental professionals, including: a new range of handpieces in the Synea range; the new Assistina $3 \mathrm{X} 3$, the most thorough handpiece cleaning and lubrication system currently available; the Piezomed, the minimally invasive, maximally effective surgical unit; the new range of surgical handpieces including the WS-91, the first high-speed contra-angle handpiece with a $45^{\circ}$ head and 1:2.7 ratio.

View the latest decontamination equipment range, with options available to suit individual budgets and requirements. Decontamination equipment including the ThermoKlenz washer disinfector dryer and Lisa steriliser are available for an affordable monthly fee under the WetH Rental Scheme. The Implantmed surgical system is unbeatable for precision, ease of use and reliability. Also on display will be the full range of oral hygiene products including the Tigon+ ultrasonic treatment unit and the award winning Facelight caries detection unit.

Visit WEH on stand H10 for unbeatable show promotions, to meet the Specialist Team and try both new and established products. Or you can call 01727874990.

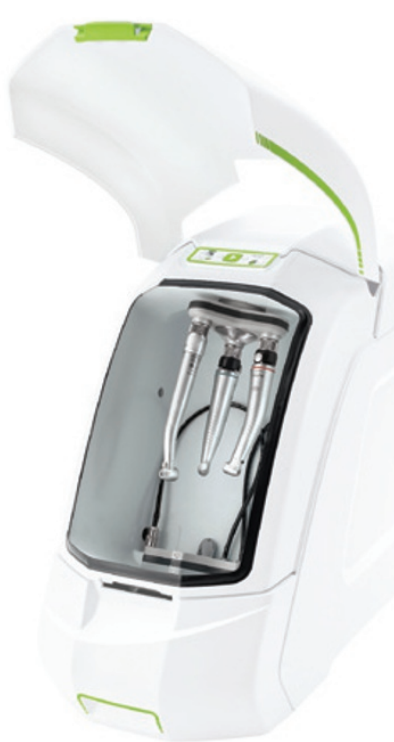

\section{DEFEAT CROW'S FEET AND SAGGING JOWLS}

Visitors to BDTA Showcase will have an opportunity to hear Dr Nick Mohindra, inventor of the Oralift facial rejuvenation device, deliver a mini lecture on its benefits on Thursday 17 October (4.30 pm), Friday 18 October (11 am) and Saturday 19 October (12.30 pm). There will also be the opportunity to attend a Practical Demonstration in the Live Theatre on the Thursday (1-2 pm) and Friday (3.30-4.30 pm), and to speak directly to Nick on Stand P15 throughout Showcase.

The Oralift device is designed to reduce and delay the signs of facial ageing (crow's feet, wrinkles, loss of skin tone, sagging jowls etc) without the need for surgery, needles or artificial fillers.

Oralift is a thermoplastic bite-guard which is easy to fit over the mandibular teeth like a mouthguard. Requiring no

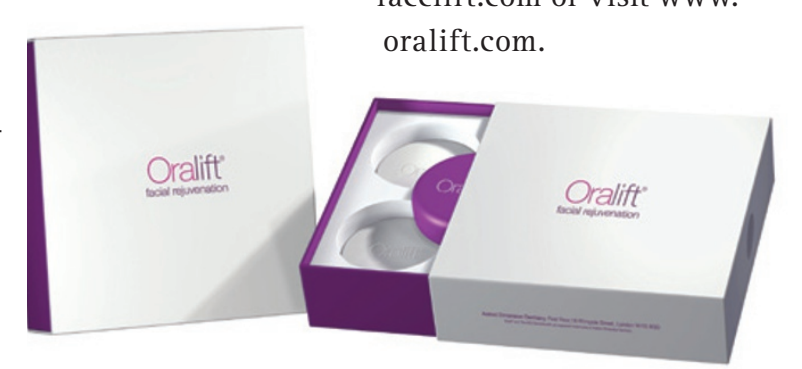

exercise programme, the facial
muscles are simply activated to create the rejuvenating effect by just wearing it in the mouth. After a matter of weeks, patients will start to notice Oralift's rejuvenating effects, which
become stronger and more pronounced as they continue

For further information about Oralift emailinfo@dental facelift.com or visit www.

\section{is set to be marked by the best line-up of speakers to date. \\ Visitors to the BACD stand will be able to learn more about the many great benefits of becoming a BACD mem- ber, which includes discounts on education events, and the chance to enrol on the BACD's 'career pathway' through cosmetic dentistry. Delegates can also learn more about the upcoming conference in Novem- ber, and chat to members of the BACD board. www.bacd.com \\ be held at the Hilton London Metropole hotel on \\ 7-9 November, and as the $10^{\text {th }}$ anniversary event, tistry (BACD) will be on hand at this year's BDTA Dental Showcase to share their passion and enthu- siasm for 'getting better at what they do'. education, the BACD is committed to providing a comprehensive educational programme across the the BACD Roadshow also regularly tours the UK, and the year climaxes with the BACD Annual Con- ference in November. This year's conference will \\ CLINICAL EXCELLENCE
THROUGH EDUCATION \\ Members of the British Academy of Cosmetic Den-}

